\title{
NEPHROPROTECTIVE ROLE OF ZINC AGAINST THE AMMONIUM SULFATE TOXICITY IN MALE ALBINO RATS
}

\author{
SIVA KUMAR TEKURI, SHOBHA RANI AMURU, PURUSOTHAM BASSAIAHGARI, YUVARANJANI GALI, \\ NEERAJA PABBARAJU*
}

Department of Zoology, Sri Venkateswara University, Tirupati, Andhra Pradesh, India. Email: pneeraja.bio2015@gmail.com Received: 05 December 2018, Revised and Accepted: 10 January 2019

\begin{abstract}
Objective: Intention of the present study is to investigate the protective role of zinc against ammonium sulfate (AS) toxicity in renal tissue by evaluating certain biochemical activities of albino rats.

Methods: Rats were divided into four groups, namely control, ammonia, zinc, and ammonia + zinc. Rats were exposed to AS (18.3 mg/kg body weight) or zinc chloride ( $4 \mathrm{mg} / \mathrm{kg}$ body weight) or both through intraperitoneally for 7-day experimentation with 24 -h time interval.

Results: Increased levels of ammonia, urea, glutamine, glutamine synthetase, free amino acids, lactate dehydrogenase, and decreased levels of total proteins, pyruvate, succinate dehydrogenases and malate dehydrogenase have been observed in AS-treated rats when compared with the control group. Supplementation of zinc mitigated AS-induced oxidative stress and restored all the biochemical parameter activities. Zinc administered to normal rats did not exhibit any significant changes in any of the parameters studied.
\end{abstract}

Conclusion: According to this study, one can conclude that the zinc supplementation has effectively recovered the mitochondrial enzyme activities and ammonia metabolic biochemical parameters in renal tissue of the AS-treated rats.

Keywords: Ammonium sulfate, Zinc chloride, Renal tissue, Oxidative enzymes, Hyperammonemia.

(C) 2019 The Authors. Published by Innovare Academic Sciences Pvt Ltd. This is an open access article under the CC BY license (http://creativecommons. org/licenses/by/4. 0/) DOI: http://dx.doi.org/10.22159/ajpcr.2019.v12i3.31030

\section{INTRODUCTION}

Ammonium sulfate (AS) is one of the inorganic popular fertilizers in the agriculture field used for the increasing of crop yield. Ammonium compounds are also used in food and beverage industries and printing industries. Utilization in excess of nitrogenous pollutants actually enters the aquatic ecosystem and runoff from land and industrial sewage, results in toxic effect on living forms as well as terrestrial forms through the food chain, and accumulated in their body [1]. The excessive production of ammonium levels in the body is associated with the using of antiepileptic and chemotherapeutic drugs such as valproic acid, salicylate, L-asparaginase, infections, and structural defects [2,3]. Ammonium absorbed by the digestive gut is metabolized to urea in the liver and eliminated through renal organ [4]. Insufficient removal of ammonia in the liver [5] or portacaval shunting causes an increase of ammonia levels in the brain [6], which are responsible for the development of hyperammonemia. Hyperammonemia consequently leads to hepatic encephalopathy [7] and kidney disorder. The major toxic effects of ammonia likely involve changes in cellular $\mathrm{pH}$ and the depletion of certain citric acid cycle intermediates, in particular, alpha-ketoglutarate [8]. Several studies also revealed the impact of ammonium-related compounds (chloride, acetate, nitrate, and sulfate) on renal functions [9-12]. In spite of extensive investigations, the precise was to investigate the anti-hyperammonemia drugs for therapeutic role against the ammonia-induced stress which are not reported.

In the present study, zinc selected as a therapeutic drug against the ammonia stress. Zinc is a well-known multipurpose ubiquitous trace element and required for indispensable growth and development of microorganisms, plants, and animals. A sufficient intake of zinc is important for as it supports the body to regulate the key functions including cell proliferation, immune functions, protein synthesis, cell division, carbohydrate metabolism, DNA synthesis, and reproductive functions [13-15]. Zinc protects the cell from oxidative stress through scavenging of reactive oxygen species (ROS) by the generation of free radicals in metabolic acidosis in diseased conditions [16]. Previous studies also revealed the zinc protective role on kidney necrosis against the cadmium, cisplatin, gentamicin, and lead toxicity [17-20]. Zinc supplementation inhibits the acute kidney disorders in hemodialysis patients [21]. The increased levels of urea and creatinine levels are reduced by zinc supplementation in liver cirrhosis patients [22]. The unique properties of zinc may have significant therapeutic benefits in several diseases in humans. Although many in vivo and clinical trials have been conducted using these dietary supplementations, their biochemical and chemical mechanisms of efficacy are the focus of much current research.

Therefore, the intention of the present study is to investigate the influence of zinc on activity levels of ammonia, urea, glutamine, glutamine synthetase, total proteins, free amino acids, pyruvate, and oxidative enzymes such as malate dehydrogenase (MDH), lactate dehydrogenase (LDH), and succinate dehydrogenase (SDH) in animal model of AS-induced stress conditions.

\section{METHODS}

Experimental animals

Male Wistar strain rats were purchased from the certified dealer (Raghavendra Enterprises, Bangalore, India) and used in the present study as an experimental model. Rats were housed in polypropylene cages lined with sterilized paddy husk as bed linen material and renewed every $24 \mathrm{~h}$ with ad libitum access to tap water and rat chew (purchased from Sai Durga Agencies, Bangalore, India). The animals maintained in well a controlled environment $\left(25 \pm 2^{\circ} \mathrm{C}\right)$ with a 12 -h light and 12-h dark cycle. The experiments were carried out in accordance with the guidelines of the Institutional Animal Ethical Committee, Sri Venkateswara University, Tirupati, India (Resolution Number: 06/2012-2013/(I)/(a) CPCSEA/IAEC/SVU/PN-ASR/dt. 01.02.2012). 


\section{Experimental design}

The total of 24 healthy adult Wistar rats was used for the present study and they were divided into four groups containing six animals in each: Group I: Served as control, Group II: animals treated with AS (18.3 mg/kg bw; i. p), Group III: animals treated with zinc chloride $\left(\mathrm{ZnCl}_{2}\right)(4 \mathrm{mg} / \mathrm{kg}$ bw; i. p) for comparing with the control group, and Group IV: animals treated with AS along with $\mathrm{ZnCl}_{2}$, for 7 days within $24 \mathrm{~h}$ time interval. The control and experimental animals at the end of the $7^{\text {th }}$ day were fasted overnight and sacrificed by cervical dislocation. Kidney tissues excised immediately, rinsed in icechilled normal saline, kept in a deep freezer at $-20^{\circ} \mathrm{C}$, and used for biochemical analysis.

\section{Biochemical analysis}

Ammonia and urea levels in kidney tissue were estimated by the methods of Bergmeyer [23] and Natelson [24]. Glutamine was estimated by the acid hydrolysis method as described by Colowick and Kalpan [25]. The activity of glutamine synthetase was estimated by the method of Chung [26]. The total protein, total free amino acids, and pyruvic acid levels were estimated by the method of Lowry et al. [27], Moore and Stein [28], and Friedman and Hangen, respectively [29].

\section{Assay of the oxidative metabolic enzymes \\ Lactate dehydrogenase}

LDH was assayed by measuring the formation of NAD from NADPH during the reduction of pyruvate according to the method of Nachlas et al. [30] as slightly modified by Prameelamma et al. [31]. The weighed renal tissue homogenate $(10 \%)$ in ice-cold 0.25 -m sucrose solution and centrifuged at $1000 \mathrm{~g}$ for $15 \mathrm{~min}$ at $4^{\circ} \mathrm{C}$. Carefully collected supernatant was used for the enzyme assay. Reaction mixture final volume $(2 \mathrm{ml})$ contained $40 \mu$ moles of sodium lactate, $100 \mu$ moles of phosphate buffer (pH 7.0), $0.1 \mu$ mole of NAD, and $4 \mu$ mole of iodonitrotetrazolium (INT). Reaction mixture incubated for $30 \mathrm{~min}$ at $37^{\circ} \mathrm{C}$ and $5 \mathrm{ml}$ of glacial acetic acid added to this for Stoppard of reaction. The formazan extracted overnight in $5 \mathrm{ml}$ of toluene at $5^{\circ} \mathrm{C}$; developed color measured at $495 \mathrm{~nm}$ in spectrophotometer against the toluene blank.

\section{Succinate dehydrogenase}

The activity of SDH assayed in the liver of rats by the method of Nachlas et al., [30] as modified by Prameelamma et al. [31]. The tissue was homogenized $(10 \% \mathrm{w} / \mathrm{v})$ in $0.25 \mathrm{M}$ ice-cold sucrose solution. The homogenate centrifuged at 5000 revolutions per minute (RPM) for $30 \mathrm{~min}$ to remove cell debris and nuclei. The supernatant passed through cheesecloth and centrifuged at 16,000 RPM for 60 min to obtain the mitochondrial pellet. The washed pellet dispersed in $0.25 \mathrm{M}$ ice-cold sucrose solution and used as enzyme source. Isolation of mitochondria carried out at $4^{\circ} \mathrm{C}$. The reaction mixture in a final volume of $2.0 \mathrm{ml}$ contained $40 \mu \mathrm{M}$ of sodium succinate, $100 \mu \mathrm{M}$ of sodium phosphate buffer, $\mathrm{pH} 7.4$, and $4 \mu \mathrm{M}$ of 3-(4-iodophenyl) 3-(4-nitrophenyl)-5-phenyl tetrazolium chloride (INT). The reaction initiated by the addition of appropriate amount of enzyme protein. The incubation carried out for $30 \mathrm{~min}$ at $37^{\circ} \mathrm{C}$ in a thermostated water bath and the reaction arrested by the addition of $5 \mathrm{ml}$ glacial acetic acid. The formazan formed extracted overnight in $5 \mathrm{ml}$ of toluene at $4^{\circ} \mathrm{C}$. The intensity of the color measured at $495 \mathrm{~nm}$ in spectrophotometer (Hitachi model U, 2001) against zero time control. The SDH activity expressed as $\mu \mathrm{M}$ of formazan formed $/ \mathrm{mg}$ protein $/ \mathrm{h}$.

\section{Malate dehydrogenase}

MDH activity was determined by the method described by Nachlas et al., [30] as suggested by Prameelamma et al. [31] with slight modifications. $10 \%(\mathrm{w} / \mathrm{v})$ homogenates of the kidney tissue were prepared in ice-cold $0.25 \mathrm{M}$ sucrose solution and centrifuged at $1000 \mathrm{~g}$ for $15 \mathrm{~min}$ at $4^{\circ} \mathrm{C}$. The supernatant fraction used for enzyme assay. The reaction mixture in a final volume of $2 \mathrm{ml}$ contained 40 moles of sodium malate, 100 moles of phosphate buffer $\left(\mathrm{P}^{\mathrm{H}}-7.0\right), 0.1$ moles of NAD, and 4 moles of INT. The reaction initiated by the addition of $0.2 \mathrm{ml}$ of homogenate containing $20 \mathrm{mg}$ of tissue as an enzyme source and incubated for $30 \mathrm{~min}$ at $37^{\circ} \mathrm{C}$ and the reaction stopped by the addition of $5 \mathrm{ml}$ of the glacial acetic acid. Zero time controls maintained by the addition of $5 \mathrm{ml}$ of the glacial acetic acid before the addition of the enzyme source to the incubation mixture. The formazan formed extracted overnight into $5 \mathrm{ml}$ of toluene at $5^{\circ} \mathrm{C}$. The developed color measured at $495 \mathrm{~nm}$ in a spectrophotometer against the toluene blank.

\section{Statistical analysis}

Data were statistically analyzed using one-way analysis of variance followed by Dennett's multiple comparison test. The values $\mathrm{p}<0.05$ were considered statistically significant. The data presented as mean \pm standard deviation. All statistical tests performed using the Statistical Package for the Social Sciences (SPSS), version 16.0.

\section{RESULTS}

Ammonia, urea, glutamine, and glutamine synthetase activity levels of control and experimental animal results shown in Table 1. Under the ammonia stress, the activities of ammonia, urea, glutamine, and glutamine synthetase levels were significantly $(\mathrm{p}<0.05)$ increased when compared with a controlled group of animals. At the same time, zinc along with AS-administered group showed significant stabilized levels of biochemical activities compared with ammonium alone-treated group. Rats treated with $\mathrm{ZnCl}_{2}$ only showed no significant variation compared to control rats.

Fig. 1a-c represents the total proteins, free amino acids, and pyruvate activity levels in control and experimental groups. AS-treated group showed that reduced levels of total proteins, pyruvate activity levels, and elevated levels of free amino acid levels observed in AS-treated groups when compared with the control group. Zinc supplementation along with ammonium-administered group showed that significantly increased total proteins, pyruvate levels, and reduced levels of free amino acids as compared with ammonium-treated group. Zinc alonetreated group showed that no significant variations when compared with the control group, but there is a significant difference with ammonium-treated group.

The mitochondrial metabolic oxidative enzymes such as SDH, MDH, and LDH activity levels in control and experimental groups showed in Table 2. SHD and MDH activity levels significantly decreased, whereas LDH levels significantly increased in AS-treated groups when compared with the control group. Zinc supplementation to ammoniumadministered group showed that significantly increased SDH and MDH and reduced levels of LDH as a contrast with the ammonium-treated group. No significant variations found in zinc alone-treated group.

\section{DISCUSSION}

Ammonia plays an important role in the body to maintain several metabolic functions at required levels $(<40 \mathrm{mmol} / \mathrm{L})$ [32]. However, at excess levels, ammonia became toxic, leads to functional disturbance in central nervous system that could lead to coma and death of the animal. Therefore, to avoid the deleterious effect of ammonia, terrestrial (ureotelic) animals detoxify the ammonia by incorporating into urea by transamination and deamination process in the liver and eliminated through urine by the kidneys [33]. The current therapeutic strategies directed toward reducing circulating concentrations of ammonia. The two main pathways of ammonia detoxification are the synthesis of urea and glutamine. In the physiological state, the liver is central in urea synthesis and this forms the basis of ammonia removal [34]. In the presence of liver disease, however, loss of functional liver mass and portacaval shunting may contribute to increased ammonia levels in plasma, thus predisposing to hepatic encephalopathy [35]. In cirrhotic patients, skeletal muscles play an important role in the detoxification of ammonia to glutamine. Glutamine synthesis is, however, only a temporary method of ammonia detoxification. To remove ammonia from the body in a situation when urea synthesis compromised (as happens in liver disease) requires transport of glutamine to the kidney, where it metabolized to release ammonia, which then excreted in 
Table 1: Effect of zinc on certain biochemical changes of ammonia, urea, glutamine, and glutamine synthetase levels in control and experimental rats renal tissue

\begin{tabular}{lllll}
\hline Groups/parameter & $\begin{array}{l}\text { Ammonia }(\mu \text { moles } \\
\text { of ammonia/g wet } \\
\text { weight of the tissue) }\end{array}$ & $\begin{array}{l}\text { Urea ( } \mu \text { mole of } \\
\text { urea/g wet weight } \\
\text { of the tissue) }\end{array}$ & $\begin{array}{l}\text { Glutamine }(\mu \text { moles } \\
\text { of glutamine/g wet } \\
\text { weight of the tissue) }\end{array}$ \\
$\begin{array}{lll}\text { of glutamyl hydroxamate } \\
\text { formed/mg of tissue/h) }\end{array}$ \\
\hline Control & $4.80 \pm 0.31$ & $0.72 \pm 0.038$ & $7.8 \pm 0.57$ & $0.59 \pm 0.062$ \\
Ammonium sulfate & $8.63 \pm 0.26^{*}$ & $0.97 \pm 0.025^{*}$ & $10.78 \pm 0.72^{*}$ & $0.82 \pm 0.095^{*}$ \\
Zinc chloride & $4.90 \pm 0.27(\mathrm{NS})$ & $0.73 \pm 0.040(\mathrm{NS})$ & $7.89 \pm 0.65(\mathrm{NS})$ & $0.61 \pm 0.048(\mathrm{NS})$ \\
Ammonium sulfate+zinc chloride & $6.21 \pm 0.35^{* *}$ & $0.79 \pm 0.042^{* *}$ & $8.92 \pm 0.59^{* *}$ & $0.72 \pm 0.069^{* *}$ \\
\hline
\end{tabular}

All the values are mean of six individual observations. *Values are significantly over control at $\mathrm{p}<0.05,{ }^{* *}$ Values are significantly over ammonium sulfate at $\mathrm{p}<0.05$. NS: Not significant over control

Table 2: Changes of mitochondrial oxidative enzymes levels in the control and experimental rat's renal tissue

\begin{tabular}{llll}
\hline Groups/parameter & $\begin{array}{l}\text { MDH }(\boldsymbol{\mu} \text { moles of formozone } \\
\text { formed/mg protein/h) }\end{array}$ & $\begin{array}{l}\text { LDH ( } \boldsymbol{\mu} \text { moles of formozone } \\
\text { formed/mg protein/h) }\end{array}$ & $\begin{array}{l}\text { SDH ( } \boldsymbol{\mu} \text { moles of formozone } \\
\text { formed/mg protein/h) }\end{array}$ \\
\hline Control & $0.6887 \pm 0.014$ & $1.5087 \pm 0.0153$ & $0.5692 \pm 0.0171$ \\
Ammonium sulfate & $0.498 \pm 0.0244^{*}$ & $2.0121 \pm 0.0261^{*}$ & $0.3685 \pm 0.0271^{*}$ \\
Zinc chloride & $0.6867 \pm 0.0151(\mathrm{NS})$ & $1.4877 \pm 0.0068(\mathrm{NS})$ & $0.556 \pm 0.0143(\mathrm{NS})$ \\
Ammonium sulfate+zinc chloride & $0.564 \pm 0.0324^{* *}$ & $1.6441 \pm 0.0149^{* *}$ & $0.514 \pm 0.0106^{* *}$ \\
\hline
\end{tabular}

All the values are mean of six individual observations. *Values are significantly over control at $\mathrm{p}<0.05,{ }^{* *}$ Values are significantly over ammonium sulfate at $\mathrm{p}<0.05$. NS: Not significant over control, MDH: Malate dehydrogenase, SDH: Succinate dehydrogenase, LDH: Lactate dehydrogenase

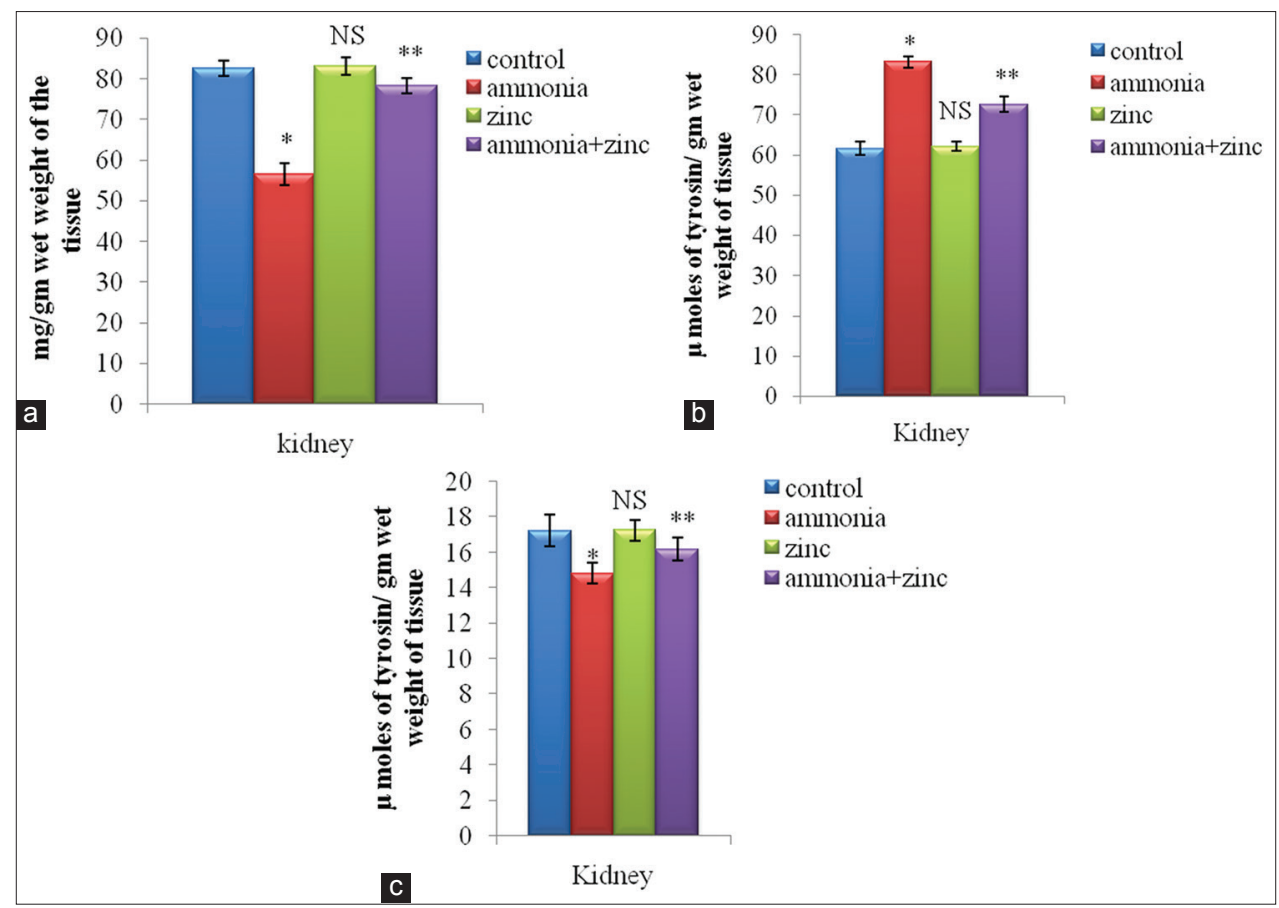

Fig. 1: (a) The total protein levels in renal tissue of albino rats exposed to ammonium sulfate and zinc chloride and effect of zinc chloride along with ammonium sulfate-treated rats. * -Values are significantly over control at $\mathbf{p}<\mathbf{0 . 0 5}$, NS - Values are not significant over control, ** - Values are significantly over ammonium sulfate at $\mathbf{p}<\mathbf{0 . 0 5}$. (b) The free amino acids levels in renal tissue of albino rats exposed to ammonium sulfate and zinc chloride and effect of zinc chloride along with ammonium sulfate-treated rats. * Values are significantly

over control at $\mathbf{p}<0.05$, NS - Values are not significant over control, ${ }^{* *}$ - Values are significantly over ammonium sulfate at $\mathbf{p}<0.001$.

(c) The pyruvate levels in renal tissue of albino rats exposed to ammonium sulfate and zinc chloride and effect of zinc chloride along with ammonium sulfate-treated rats. * - Values are significantly over control at $\mathbf{p}<0.05$, NS - Values are not significant over control, ** - Values are significantly over ammonium sulfate at $\mathrm{p}<0.001$

urine [34]. Renal nitrogen excretion consists almost completely of urea and ammonia. The two major components of renal nitrogen excretion, urea and ammonia, regulated by a wide variety of conditions and play important roles in normal health and disease, including roles in the urine concentrating mechanism and in acid-base homeostasis [36].

Kidneys are main homeostatic organs in the body, they perform the two essential roles; first, they eliminate the nitrogenous products from the body, and second, they regulate the minimum needed constituents of the body fluids. Urea, uric acid, ammonia, and creatine are the renal markers for analysis of kidney functions. Urea is a major nitrogenous end product of proteins and amino acid catabolism. In the kidneys, urea filtered out of the blood by the glomerular and partially reabsorbed with water. Creation is a catabolic product of the creatine phosphate in muscle and usually eliminated by the kidneys. If any alterations in the renal markers, it will lead to structural and functional changes in the kidneys. 
In the current study, ammonia and urea levels exhibited a significant increment in AS-treated rats. This increase in ammonia levels may be due to the degradation of proteins, leading to elevation of free amino acids in the body fluids. The excessive levels of free amino acids enhance the ammonia and urea production. Our results revealed that the concentration of urea was significantly elevated in the AS-treated group compared to control group. The slight and significant rise in the urea levels may be due to the impairment of the glomerular function and tubular damage to the kidneys under hyperammonia stress. The elevated levels of urea and ammonia (end products) in renal tissue, especially urea, indicate poor clearance of these substances by the kidneys rather than the excessive production. The hyperammonia stress may cause the increase in the hydrogen ion $(\mathrm{pH})$ concentration in renal tubules, probably leading to acidosis in renal tubules and affect the glomerular filtration and tubular secretion because the kidneys work at particular pH levels [33]. The acidosis causes the renal injury, leads to functional alteration and impairment of elimination of end products properly. Thenmozhi and Subramanian reported that ammonium chloride treatments caused significant increase in blood ammonia and plasma urea in albino rats [37]. Ammonium acetate-treated rats also showed the increased levels of ammonia and urea levels in blood. The increased levels of urea and ammonia levels [8] indicate that hyperammonemia stress might induce oxidative stress in renal tissue and that lead to generation of free radicals and ROS and probably lead to hydrogen ion levels in renal tubules. Elevated levels of $\mathrm{H}+$ ion concentration represent the increasing the acidosis. Interestingly, our results indicated that coadministration of $\mathrm{ZnCl}_{2}$ to AS-treated group restored ammonia and urea concentrations within normal limits. Hence, it clearly indicates that zinc supplementation might inhibit the hyperammonemia stress and alteration of ammonia, urea levels restored to normal conditions. Previous studies also reported that zinc supplementation successfully prevents the alteration of renal markers by toxic substances. Babaknejad et al. studied the zinc and magnesium combined protective role against the cadmium-induced nephrotoxicity in rats, the elevated levels of renal markers such as urea and creatine levels restored successfully in zinc-administered rats [38]. Mesquita et al. reported that the mercury chloride-induced renal marker alterations have been reduced by the zinc supplementation in female rats. Increased levels of serum urea, creatine, and urine protein levels restored by zinc supplementation in gentamicin nephrotoxicity [39]. Another study also reported a nephroprotective role of zinc against gentamicin-induced renal failure in male albino rats, the elevated levels of serum ammonia, urea, and urinary protein levels were stabilized by $\mathrm{ZnCl}_{2}$ supplementation and renal morphological structure resorted to normal [19]. Zinc deficiency leads to renal failure as well as the reason behind to chronic kidney disorder. Adequate supplementation of zinc to the chronic kidney disorder patient improves the renal tubular functions by stabilizing acidosis through decreased levels of nitrogen excess materials (urea, ammonia, and creatine) [40].

Glutamine is quantitatively the most important donor of $\mathrm{NH}_{3}$ in the kidney. The $\mathrm{NH}_{3}$ cleaved from glutamine by the action of phosphatedependent glutaminase, which subjected to $\mathrm{pH}$ regulation [41]. The carbon skeleton of glutamate in the kidney, created by the action of glutaminase, is converted through the formation of 2-oxoglutarate, succinate, fumarate, malate, and oxaloacetate to phosphoenolpyruvate (or malate to pyruvate directly) and then participates in gluconeogenesis. The glucose produced by this pathway provides up to $25 \%$ of circulating plasma glucose in vivo [42]. Glutamine enzyme controlled the ammonia production. Glutaminase enzyme removes the amide nitrogen from glutamine by hydrolytic reaction and liberates the ammonia. The glutamine reaction, unlike the glutamine synthetase reaction, does not involve the participation of adenine nucleotides and this strongly favors glutamate formation [43]. The other functional pathways to eliminate the ammonia toxicity are formed by the production of glutamine through the involvement of glutamine synthetase [44] which catalyzes the adenosine triphosphate (ATP)-dependent synthesis of glutamine from glutamate and ammonia. In addition, this enzyme has a major role in nitrogen metabolism since the amide group of glutamine and nucleotides is present [45]. In the present investigation, increased levels of glutamine synthetase in AS-treated rats observed. This indicates high mobilization of glutamate for the synthesis of glutamine. The results of glutamine levels were also in accordance with their findings. Glutamine synthetase catalyzes the ATP-dependent condensation of glutamate with ammonia to yield glutamine [46]. ATP phosphorylates glutamate to form adenosine diphosphate (ADP) and an acyl phosphate intermediate, r-glutamyl phosphate, which reacts with ammonia, forming glutamine, and inorganic phosphate. ADP and inorganic phosphate do not dissociate until ammonia binds and glutamine is released [47].

In the present study, the activity levels of total proteins and pyruvate levels decreased, and free amino acid levels increased under AS treatment compared with control. AS toxicity may lead to degradation of proteins in kidney tissue. The depletion of the protein fraction in kidney tissue may be due to their degradation and possible utilization for metabolic purposes. An increase in free amino acid levels was the result of the breakdown of protein for energy and impaired incorporation of amino acids in protein synthesis. The toxicants might affect the hormonal balance, which directly or indirectly affect the tissue protein levels. Free amino acids considered to act as a connecting link between protein and carbohydrate metabolism. The liver is an exclusive site for the metabolism of several amino acids and the free amino acid content of the liver known to change during physiological and pathological conditions [48]. The amino acids released during protein degradation due to activation of proteolysis will once again return to the amino acid pool, and thus, the free amino acids are the currency through which protein metabolism operates showing the interdependence of both amino acids and proteins [48]. Thus, sublethal dose of AS gave an increment of free amino acids levels probably due to ammonia stress. Pyruvate is the terminate metabolite of glycolysis under aerobic conditions. The level of pyruvate indicates the efficiency of oxidative metabolism. Decreased pyruvate levels indicate its role as a precursor for another product in the metabolism such as conversion to lactate or to form amino acids, lipids, and triglycerides. The conversion of pyruvate to lactate under anaerobic conditions favor the reoxidation of $\mathrm{NADH}_{2}$ which allows glycolysis to proceed in the absence of oxygen by generating sufficient NAD for the reaction catalyzed by glyceraldehyde 3-phosphate dehydrogenase. Decrement in pyruvic acid levels with increment in lactate levels suggests a shift in cellular respiratory metabolism, toward anaerobiosis as a prelude toward adaptability to cope with the enhanced energy demands. Cyclic adenosine monophosphate activates the phosphorylase system during stress condition and inhibits the pyruvate levels, thus increasing the lactate content [49]. The elevated levels of free amino acids and decreased levels of proteins, and pyruvate levels were restored in zinc coadministered rats with AS. Hence, zinc seems to prevent the degradation of proteins in renal tissue and conversion of free amino acids to lactate and lipids by activation of Krebs cycle intermediates.

The mitochondrial oxidative enzymes such as MDH, SDH, and LDH levels showed in Table 2. MDH catalyzes the conversion of oxaloacetate and malate utilizing the NAD/NADH coenzyme system [50]. MDH is a rather ubiquitous enzyme, in which several isoforms have been identified, dithering in their subcellular localization and their specialty for the coenzyme NAD or NADP. The activity of MDH depends on the rates of the formation of oxaloacetate and phosphoenolpyruvate from malate. Any change in the mitochondrial structure inhibits the activity of $\mathrm{MDH}$; the cytosolic and mitochondrial forms of $\mathrm{MDH}$ are key enzymes in the malate-aspartate shuttle [51]. The activity levels of MDH indicate the status of prevailing oxidative metabolism. In the present investigation, decreased levels of MDH in AS-treated rats observed. The decrease in the specific activity of MDH in kidney tissue of rats due to ammonia treatment suggests decreased utilization of malate. The reduced levels of tricarboxylic acid cycle (TCA) intermediates may also be due to the decrease in MDH activity during AS-treated rats. Concisely, the reduced MDH activity attributed to (1) low availability of substrate, (2) lesser conversion of succinate-fumarate-malate, and (3) the changes in the 
structural integrity of mitochondria. A significant decrease in the specific activity of NADP-ICDH and due to AS treatment observed in the present study indicates reduced formation of malate.

LDH is a cytosolic enzyme, which allows the assessment of the process of anaerobic energy production by the cell [52]. This enzyme is a marker of metabolic activity of the renal glomerular function. Elevated levels of LDH represent the alteration of respiratory cycle mechanism because adequate levels of LDH needed for energy production by anaerobic process while LDH levels are increased it mostly activates the synthesis of lactate, accumulation of lactate leads to the formation of oxidative stress and disturbance of other mitochondrial enzymes (MDH and SDH). SDH, an enzyme of the TCA cycle, is a marker of the electron transport system in the inner membrane of the mitochondrion [53]. The changes observed in its activity due to chronic exposure to AS indicate disorders in the respiratory mechanisms in cells and damage to the mitochondrial membranes. These are located in the main tubules (i.e., proximal convoluted tubules and straight tubules) and distal convoluted tubules. Cisplatin-induced toxicity leads to elevated levels of LDH, urea, and creatinine phosphokinase in albino mice [54]. Priyadarshini and Neeraja reported that AS treatment causes the increment of LDH and decrement of MDH, SDH levels in liver, kidney, and testis tissues of male rats [55].

The current study showed that the decreased levels of MDH and SDH and increased levels of LDH stabilized in the zinc coadministered rats compared with AS-treated rats. However, the zinc-supplemented rats were not indicated significant variation with control rats. Therefore, it clearly indicates that zinc supplementation to AS improves the functioning of mitochondrial enzymes in the renal tissue of rat. Elevated LDH levels stabilized and decreased levels of MDH and SDH increased with zinc supplementation.

\section{CONCLUSION}

The present study demonstrated that AS is a toxic element that causes alteration of renal markers and biochemical parameters. AS treatment leads to hyperammonemia condition in rats. $\mathrm{Zn}$ administration with AS proved a protective role in experimental AS-induced acute renal failure. The treatment with $\mathrm{Zn}$ significantly diminished the alteration of renal function, with evidence through stabilization of renal markers (urea and ammonia), glutamine, and glutamine synthase levels. Zn supplementation also decreased free amino acid levels, LDH levels being significantly higher after $\mathrm{Zn}$ administration with AS. The decreased levels total proteins, pyruvate, MDH and SDH were restored with zinc supplementation. The obtained results showed that zinc supplementation prevents the hyperammonemia stress.

\section{ACKNOWLEDGMENT}

T. Siva Kumar (SRF) grateful to University Grants Commission, New Delhi, India, for awarding BSR-RFSMS/SRF research fellowship to carry out this work.

\section{AUTHORS' CONTRIBUTIONS}

PN designed the experimental work and supervision of the study. SK did the experimental work and drafting the manuscript. SR, PB, and YG helped in biochemical estimation, statically analysis, graphs, and editing of MS.

\section{CONFLICTS OF INTEREST}

Authors declare that they have no conflicts of interest.

\section{REFERENCES}

1. Kumar TS, Rani AS, Sujatha K, Purushotham B, Neeraja P. Toxicity evaluation of ammonium sulfate to albino rat. Asian J Pharm Clin Res 2017;10:313-6.

2. Auron A, Brophy PD. Hyperammonemia in review: Pathophysiology, diagnosis, and treatment. Pediatr Nephrol 2012;27:207-22.
3. Cattaneo CI, Ressico F, Valsesia R, D'Innella P, Ballabio M, Fornaro M, et al. Sudden valproate-induced hyperammonemia managed with L-carnitine in a medically healthy bipolar patient: Essential review of the literature and case report. Medicine (Baltimore) 2017;96:e8117.

4. Acar A, Yalçin E, Çavuşoğlu K. Protective effects of $\beta$-carotene against ammonium sulfate toxicity: Biochemical and histopathological approach in mice model. J Med Food 2018;21:1145-9.

5. Meijer AJ, Lamers WH, Chamuleau RA. Nitrogen metabolism and ornithine cycle function. Physiol Rev 1990;70:701-48.

6. Butterworth RF. Effects of hyperammonaemia on brain function. J Inherit Metab Dis 1998;21 Suppl 1:6-20.

7. Butterworth RF. Pathogenesis of hepatic encephalopathy and brain edema in acute liver failure. J Clin Exp Hepatol 2015;5:S96-103.

8. Lena PJ, Subramanian P. Effects of melatonin on the levels of antioxidants and lipid peroxidation products in rats treated with ammonium acetate. Pharmazie 2004;59:636-9.

9. Subash S, Subramanian P. Impact of morin (a bioflavonoid) on ammonium chloride-mediated oxidative damage in rat kidney. Int $\mathbf{J}$ Nutr Pharmacol Neurol Dis 2011;1:174-8.

10. Lena PJ, Subramanian P. Nephroprotective effects of melatonin in hyperammonemia induced oxidative stress in wistar rats. Int $\mathrm{J}$ PharmTech Res 2015;8:74-8.

11. Messaadia A, Saka S, Krim M, Maidi I, Aouacheri O, Djafer R. Gingersupplemented diet ameliorates ammonium nitrate-induced oxidative stress in rats. Afr J Biotechnol 2013;12:5909-16.

12. Kumar TS, Neeraja P. Ameliorative effect of zinc on ammonia induced alterations in antioxidant enzyme levels in kidney tissue of albino rat. Asian J Pharmacol Toxicol 2015;3:31-5.

13. Roohani N, Hurrell R, Kelishadi R, Schulin R. Zinc and its importance for human health: An integrative review. J Res Med Sci 2013;18:144-57.

14. Brand IA, Kleineke J. Intracellular zinc movement and its effect on the carbohydrate metabolism of isolated rat hepatocytes. J Biol Chem 1996;271:1941-9.

15. Fallah A, Mohammad-Hasani A, Colagar AH. Zinc is an essential element for male fertility: A review of $\mathrm{Zn}$ roles in men's health, germination, sperm quality, and fertilization. J Reprod Infertil 2018;19:69-81.

16. Marreiro DD, Cruz KJ, Morais JB, Beserra JB, Severo JS, de Oliveira AR, et al. Zinc and oxidative stress: Current mechanisms. Antioxidants (Basel) 2017;6:e24.

17. Obaiah J, Rani AU. Mitigating role of zinc and iron against cadmium induced toxicity in liver and kidney of male albino rat: A study with reference to metallothionein quantification. Int J Pharm Pharm Sci 2014;6:411-7.

18. Tuzcu M, Sahin N, Dogukan A, Aslan A, Gencoglu H, Ilhan N, et al. Protective role of zinc picolinate on cisplatin-induced nephrotoxicity in rats. J Ren Nutr 2010;20:398-407.

19. Teslariu O, Pasca AS, Mititelu-Tartau L, Schiriac CE, Gales C, Saftencu PM, et al. The protective effects of zinc in experimental gentamicin induced acute renal failure in rats. J Physiol Pharmacol 2016;67:751-7.

20. Soussi A, Gargouri M, El Feki A. Effects of co-exposure to lead and zinc on redox status, kidney variables, and histopathology in adult albino rats. Toxicol Ind Health 2018;34:469-80.

21. Neto LC, Bacci MR, Sverzutt LC, Costa MG, Alves BC, Fonseca FL. The role of zinc in chronic kidney disease patients on hemodialysis: A systematic review. Health 2016;8:344-52.

22. Grüngreiff $\mathrm{K}$, Reinhold $\mathrm{D}$, Wedemeyer $\mathrm{H}$. The role of zinc in liver cirrhosis. Ann Hepatol 2016;15:7-16.

23. Bergmeyer HV, editor. Methods of Enzymatic Analysis. New York: Academic Press; 1965. p. 401

24. Natelson S. Technique of Clinical Chemistry. Illinois: Publisher Thomas C.C., Spring Field; 1971. p. 261-728

25. Colowick SP, Kalpan NO. Methods of Engymology. New York: Academic Press; 1957. p. 501

26. Chung WU. Glutamine synthetase-I: A comparative study of its inhibition by DL-amino hydroxyl-lysine. Comp Biochem Physiol 1963;8:335-51.

27. Lowry OH, Rosebrough NJ, Farr AL, Randall RJ. Protein measurement with the folin phenol reagent. J Biol Chem 1951;193:265-75.

28. Moore S, Stein WH. A modified ninhydrin reagent for the photometric determination of amino acids and related compounds. J Biol Chem 1954;211:907-13.

29. Friedman TE, Hangen GE. Pyruvic acid I. Collection of the blood for determination of lactic acid. J Biol Chem 1942;147:67.

30. Nachlas MM, Margulies SI, Seligman AM. A colorimetric method for the estimation of succinic dehydrogenase activity. J Biol Chem 
1960;235:499-503

31. Prameelamma Y, Rao KV, Swami KS. Regulation of succinate dehydrogenase activity in gastrocnemius muscle of frog Rana hexadactyla. Indian J Exp Biol 1975;13:177-9.

32. Weiner ID, Verlander JW. Renal ammonia metabolism and transport. Compr Physiol 2013;3:201-20.

33. Subash S, Subramanian P. Protective effect of morin on lipid peroxidation and lipid profile in ammonium chloride-induced hyperammonemic rats. Asian Pac J Trop Dis 2012;2:103-6.

34. Jalan R, Kapoor D. Enhanced renal ammonia excretion following volume expansion in patients with well compensated cirrhosis of the liver. Gut 2003;52:1041-5.

35. Liere V, Sandhu G, DeMorrow S. Recent advances in hepatic encephalopathy. F1000Res 2017;6:1637.

36. Weiner ID, Mitch WE, Sands JM. Urea and ammonia metabolism and the control of renal nitrogen excretion. Clin J Am Soc Nephrol 2015;10:1444-58.

37. Thenmozhi AJ, Subramanian P. Antioxidant potential of Momordica charantia in ammonium chloride-induced hyperammonemic rats. Evid Based Complement Alternat Med 2011;2011:612023.

38. Babaknejad N, Moshtaghie AA, Nayeri H, Hani M, Bahrami S. Protective role of zinc and magnesium against cadmium nephrotoxicity in male wistar rats. Biol Trace Elem Res 2016;174:112-20.

39. Mesquita M, Pedroso TF, Oliveira CS, Oliveira VA, do Santos RF, Bizzi CA, et al. Effects of zinc against mercury toxicity in female rats 12 and 48 hours after hgCl2 exposure. EXCLI J 2016;15:256-67.

40. Yonova D, Vazelov E, Tzatchev K. Zinc status in patients with chronic renal failure on conservative and peritoneal dialysis treatment. Hippokratia 2012;16:356-9.

41. Gstraunthaler G, Holcomb T, Feifel E, Liu W, Spitaler N, Curthoys NP, et al. Differential expression and acid-base regulation of glutaminase mRNAs in gluconeogenic LLC-PK(1)-FBPase(+) cells. Am J Physiol Renal Physiol 2000;278:F227-37.

42. Newsholme P, Lima MM, Procopio J, Pithon-Curi TC, Doi SQ, Bazotte RB, et al. Glutamine and glutamate as vital metabolites. Braz J Med Biol Res 2003;36:153-63.
43. Cooper AJ. The role of glutamine synthetase and glutamate dehydrogenase in cerebral ammonia homeostasis. Neurochem Res 2012;37:2439-55.

44. Norenberg MD. Distribution of glutamine synthetase in the rat central nervous system. J Histochem Cytochem 1979;27:756-62.

45. Milman G, Portnoff LS, Tiemeier DC. Immunochemical evidence for glutamine-mediated degradation of glutamine synthetase in cultured Chinese hamster cells. J Biol Chem 1975;250:1393-9.

46. Liaw SH, Kuo I, Eisenberg D. Discovery of the ammonium substrate site on glutamine synthetase, a third cation binding site. Protein Sci 1995;4:2358-65

47. Eisenberg D, Gill HS, Pfluegl GM, Rotstein SH. Structure-function relationships of glutamine synthetases. Biochim Biophys Acta 2000;1477:122-45.

48. Murray RK, Granner DK, Mayes PA, Rodwell VW. In: Harper's Illustrated Biochemistry. International $26^{\text {th }}$ ed. New Delhi: The McGraw-Hill Companies, Inc.; 2007. p. 46-7.

49. Santhi K. Histological and Metabolic Changes in Selected Tissues of the Fish, Oreochromis Massambicus under Chronic Ammonia Stress. Tirupati: Ph.D. Thesis Submitted to S. V. University; 1991.

50. Minárik P, Tomásková N, Kollárová M, Antalík M. Malate dehydrogenases--structure and function. Gen Physiol Biophys 2002;21:257-65.

51. Chatterjea MN, Shinde R. Text Book of Medical Biochemistry. $1^{\text {st }}$ ed. New Delhi: Jaypee Brothers Medical Publishers Pvt., Ltd.; 1993. p. $258-80$

52. Lemire J, Mailloux RJ, Appanna VD. Mitochondrial lactate dehydrogenase is involved in oxidative-energy metabolism in human astrocytoma cells (CCF-STTG1). PLoS One 2008;3:e1550.

53. Rutter J, Winge DR, Schiffman JD. Succinate dehydrogenase assembly, regulation and role in human disease. Mitochondrion 2010;10:393-401.

54. Ali M, Mruthunjaya K, Nandini C, Nabeel K, Manjula SN. Chemoprotective effect of noni (Morinda citrifolia L.) fruit juice against cisplatin-induced nephrotoxicity. Int J Pharm Pharm Sci 2016;8:105-10.

55. Priyadarshini J, Neeraja P. Impact of ammonia on oxidative metabolism in certain tissues of albino rat. Int J Pharm Bio Sci 2015;6:215-21. 